\title{
About 2 Cases of Accidental Discovery of Broncholithiasis
}

\author{
Harmouchi Hicham ${ }^{*}$, Rabiou Sani ${ }^{1}$, Sidibe Kassim², Issoufou Ibrahim ${ }^{1}$, Belliraj Layla1, \\ Ammor Fatimazahra1, Lakranbi Marouane1, Ouadnouni Yassine1,3, Smahi Mohammed ${ }^{1,3}$ \\ ${ }^{1}$ Department of Thoracic Surgery, CHU Hassan II of Fez-Morocco, Fez, Morocco \\ ${ }^{2}$ Department of Imagery, CHU Hassan II of Fez-Morocco, Fez, Morocco \\ ${ }^{3}$ Faculty of Medicine and Pharmacy, Sidi Mohamed Ben Abdellah University, Fez, Morocco \\ Email: *harmouchi.hicham@gmail.com
}

How to cite this paper: Hicham, H., Sani, R., Kassim, S., Ibrahim, I., Layla, B., Fatimazahra, A., Marouane, L., Yassine, O. and Mohammed, S. (2018) About 2 Cases of Accidental Discovery of Broncholithiasis. Open Journal of Thoracic Surgery, 8, 37-42. https://doi.org/10.4236/ojts.2018.82007

Received: May 10, 2018

Accepted: June 23, 2018

Published: June 27, 2018

Copyright (c) 2018 by authors and Scientific Research Publishing Inc. This work is licensed under the Creative Commons Attribution International License (CC BY 4.0).

http://creativecommons.org/licenses/by/4.0/

\begin{abstract}
Broncholithiasis is the presence of calcified material in the bronchial lumen. Bronchial fibroscopy and thoracic CT are the main paraclinical elements for diagnosis. However, most broncholithiasis is fortuitous discovery intraoperatively. The evolution may be marked by complications in the underlying lung, or fistulization in the mediastinal structures especially the esophagus. Early on, management can be simple monitoring or endoscopic extraction of broncholithiasis. Surgery remains the only option in case of complications. The authors report 2 cases of broncholithiasis, one of which was diagnosed radiologically and the other of incidental discovery during the surgical exploration of a lesion of the right lower lobe.
\end{abstract}

\section{Keywords}

Broncholithiasis, Fistula, Lymphadenopathy, Tuberculosis

\section{Introduction}

Broncholithiasis is a rare pathology that corresponds to the presence of calcareous concretions in the bronchial lumen. It is secondary, most often, to the erosion of the bronchial wall by calcified ganglia, often of tubercular origin, sitting in close proximity to the bronchus. The diagnosis is based on a combination of thoracic CT and bronchial fibroscopy, but a chance finding during surgery is possible [1]. Broncholithiasis remains an unpredictable pathology of evolution, and the most feared complication remains fistulization in mediatalisal structures mainly the esophagus. We report 2 cases of broncholithiasis, one of radiological diagnosis and the other of incidental discovery during the surgical exploration of 
a lesion of the right lower lobe (Table 1 ).

\section{Observation 1}

$\mathrm{Mr} \mathrm{H}$. F, is a 61 year old patient, having as antecedent a tuberculosis ganglionnaire in childhood for more than 3 years, he has had a productive cough with muco-purulent sputum, aggravated by the occurrence of repetitive haemoptysis of low abundance. The clinical examination at its admission found asymmetry of the rib cage by retraction at the expense of the right hemithorax. The chest $\mathrm{x}$-ray showed right basi-thoracic areolar images with retraction of the trachea towards the right side and ascension of the right diaphragmatic dome (Figure 1(A)). The thoracic CT scan revealed a lower right lobar systemic parenchymal parenchymatous focus, in which there are dilated bronchi of the cylindrical type (Figure 1(B)). The search for AFB in sputum was negative. Bronchial fibroscopy showed muco-purulent sputum in the middle lobar and right lower lobar bronchus without visualization of fistula. As part of the preoperative assessment, spirometry had shown a FEV1 of $1.92 \mathrm{~L}$, or $57 \%$ of the theoretical. Transthoracic echocardiography was without abnormality. It was decided then, a lower right lobectomy. Right posterolateral thoracotomy was found to have dilated the right lower lobe bronchi in relation to calcified subcarinal adenopathy fistulated in the right lower lobe bronchus, with inflammatory magma enclosing the fistula-free esophagus of the latter. The gesture consisted of a regulated resection of the right lower lobe as well as the carenal adenopathies. The postoperative course was without particularity. The anatomopathological results of the excision specimen did not indicate tuberculosis. The mean follow-up of the patient was 3 years, with no complications.

\section{Observation 2}

It is Mrs. D. S, 57 years old, with no notable pathological history, who has been reporting a productive cough for 6 months, with muco-purulent sputum, aggravated by episodes of recurrent hemoptysis. She was in good general condition and the somatic examination was peculiar. Chest X-ray showed no abnormality. Given the repetitive nature of hemoptysis, thoracic CT showed a calcified image at the level of the intermediate trunk lumen (Figure 2), with bronchiectasis lesions of the right lower lobe. Bronchial fibroscopy had revealed purulent secretions from the right lower lobe bronchus. After a normal preoperative check-up, she was referred to the block where a right posterolateral thoracotomy was performed. The first stage consisted of the release of the esophagus from subcarenal adenopathies fistulated in both the bronchi and the esophagus. After suturing the oesophageal fistula in two mucosal and muscular planes (Figure 3), a right lower lobectomy was performed with release of the bronchus of subcarenar lymphadenopathy and lymph node dissection. The operative follow-up was simple, with strict parenteral nutrition until postoperative day 10. Control radiography with oesophageal opacification was normal. the mean follow-up of the patient was 3 years, with no complications. 
Table 1. Characteristics of patients.

\begin{tabular}{|c|c|c|}
\hline & Observation $\mathrm{N}^{\bullet} 1$ & Observation $\mathrm{N}^{\bullet} 2$ \\
\hline Sex & Men & Women \\
\hline Age & 61 & 57 \\
\hline Pathological history & tuberculosis ganglionnaire & - \\
\hline Clinical sign & $\begin{array}{l}\text {-cough with muco-purulent sputum } \\
\text {-repetitive haemoptysis of low } \\
\text { abundance }\end{array}$ & $\begin{array}{l}\text {-cough with muco-purulent } \\
\text { sputum } \\
\text {-episodes of recurrent hemoptysis }\end{array}$ \\
\hline Chest $\mathrm{x}$-ray showed & $\begin{array}{l}\text {-right basi-thoracic areolar images } \\
\text {-retraction of the trachea towards the } \\
\text { right side and ascension of the right } \\
\text { diaphragmatic dome }\end{array}$ & no abnormality \\
\hline Thoracic CT scan & $\begin{array}{l}\text {-lower right lobar systemic } \\
\text { parenchymal parenchymatous focus, } \\
\text { in which there are dilated bronchi of } \\
\text { the cylindrical type }\end{array}$ & $\begin{array}{l}\text {-calcified image at the level of the } \\
\text { intermediate trunk lumen }\end{array}$ \\
\hline Bronchial fibroscopy & $\begin{array}{l}\text {-muco-purulent sputum in the } \\
\text { middle lobar and right lower lobar } \\
\text { bronchus }\end{array}$ & $\begin{array}{l}\text {-purulent secretions from the } \\
\text { right lower lobe bronchus }\end{array}$ \\
\hline
\end{tabular}

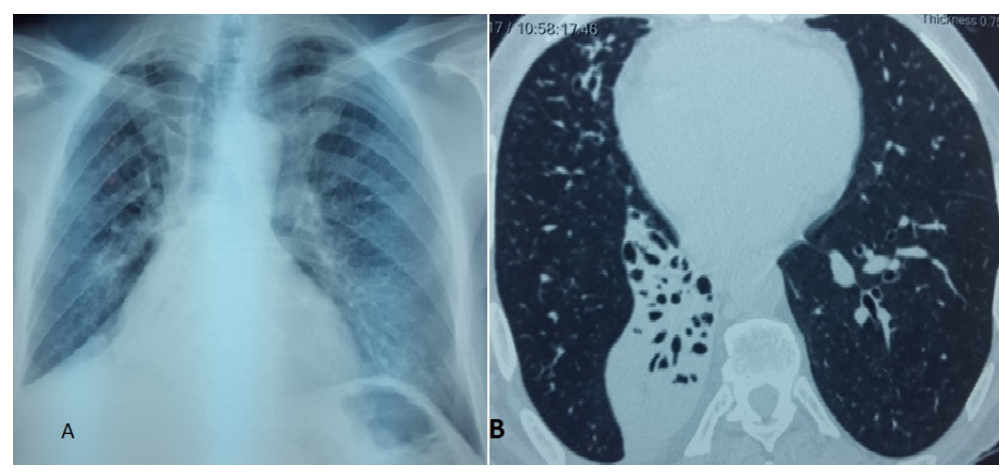

Figure 1. (A) chest radiograph showing right hemithorax retraction and tracheal retraction to the right side; (B) CT thoracic in parenchymatous window and axial cut showing a focus of parenchymatous condensation systemized lobar lower right, in which are lesions of dilations of the bronchi of the cylindrical type.

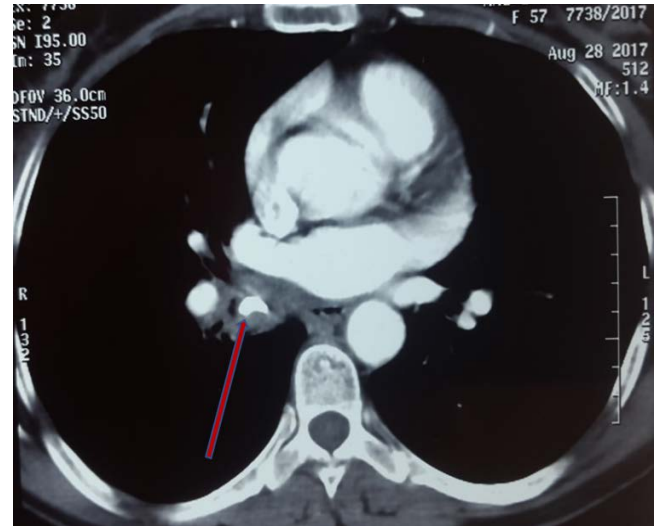

Figure 2. CT in mediastinal window showing a broncholithiasis of the intermediate trunk (arrow). 


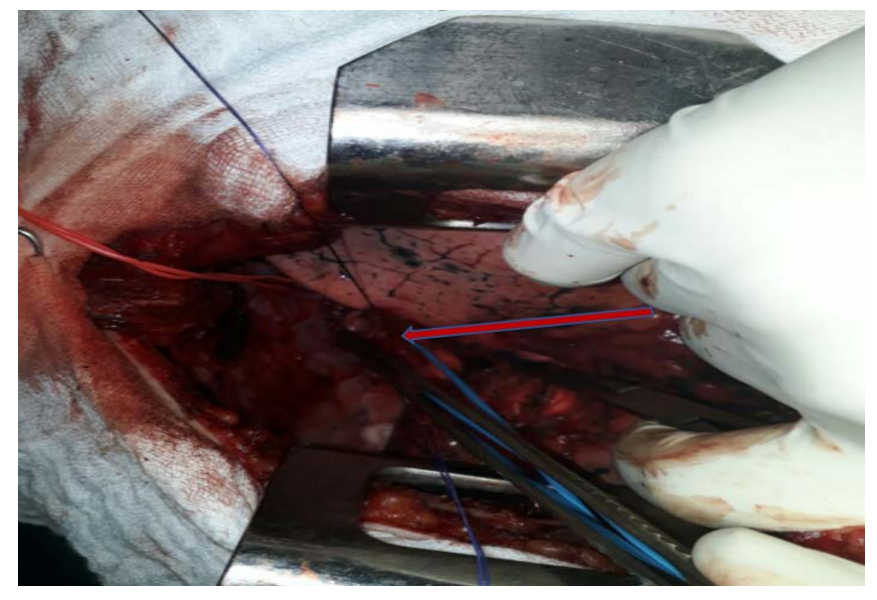

Figure 3. Operative view showing the suture of the oesophageal fistula accidentally discovered intraoperatively (arrow).

\section{Discussion}

Broncholithiasis is the presence of calcified material in the bronchial lumen secondary to the erosion of the bronchial wall by interbronchial or hilar calcified ganglia, most often of tuberculous bronchial origin [1]. The migration of these calcified ganglia is favored by respiratory and cardiac movements [2]. Lymph node calcification is frequently related to sequelae of granulomatosis, particularly tuberculosis, which remains a public health problem in our context. However, broncholithiasis may also be secondary to a calcified endobronchial tumor or more rarely to an intrabronchial calcified foreign body that has gone unnoticed [1] [3]. Broncholithiasis can remain asymptomatic, and its discovery then fortuitous, during a bronchial fibroscopy, on a thoracic CT, or during a surgical exploration. This is the case of one of our patients in whom surgical exploration has revealed a calcified adenopathy magma in contact with the right inferior lobar bronchus which is fistulized. The clinical manifestations are not specific, since the pathognomonic lithoptysis of broncholithiasis, which corresponds to the rejection of calcified material after a coughing effort, remains uncommon and can be seen only in $5 \%$ to $34 \%$ of cases [4]. Hemoptysis is frequent, often of low abundance and recurrent, due either to a systemic hypervascularization by associated lesions, in particular dilations of the bronchi, or secondary to the erosion of pulmonary vessels by broncholitis [5]. Massive haemoptysis in the context of broncholithiasis causes fear of aorto-bronchial fistulization [5] [6]. In this case, both patients had reported a concept of recurrent hemoptysis often associated with muco-purulent expectorations. In imaging, broncholithiasis often results in ventilatory disorders such as atelectasis, obstructive emphysema, or bronchial dilatation [7]. Chest X-ray remains unspecific, but may guide the diagnosis in case of hilar ganglion calcification [8]. The diagnosis of broncholithiasis is essentially made by the combination of bronchoscopic bronchoscopy, which allows the direct visualization of the broncholith in about $24 \%$ to $56 \%$ of cases, and the thoracic CT scan, which shows the endoluminal or peribronchial character of calcification [7] [9]. However, broncholithiasis may go unnoticed by 
imaging and bronchoscopy, the case of our first patient, where the diagnosis was made only at the surgical stage. As in our 2 observations, the right bronchial tree remains the predominant seat of broncholithiasis, because of the importance of ganglionic relays on the right side compared to the left side [10]. Although it is known benign, the evolution of broncholithiasis remains unpredictable. When broncholithiasis is free in the bronchial lumen, the evolution may be spontaneously resolving after expectoration of the calculus [11]. The complications are secondary to either the sequelae that it causes in the underlying lung, especially a dilation of the bronchi, or to the lesions caused by chronic compression of the mediastinal structures, mainly the esophageal fistula [9]. The latter was fortuitously discovered in our 2nd patient during the surgical exploration, without having preoperative clinical signs testifying to this oesopronchial fistula. In case of fistula, the clinical signs are mainly dominated by false roads, and paroxysmal cough paced by food. The middle third of the esophagus, which is opposite the carina, remains the preferable seat of oesophageal fistulas, contiguously from subcarinal ganglia [12]. The management of broncholithiasis depends on the symptomatology and the occurrence of secondary complications [9]. Therapeutic abstention, flexible or rigid bronchial fibroscopy, and surgery remain the main therapeutic options for broncholithiasis [9]. Faced with asymptomatic and uncomplicated broncholithiasis, only regular monitoring is recommended. Endoscopic extraction is indicated for free broncholithiasis in the bronchial tree and in the absence of complications [8] [13].

\section{Conclusion}

Broncholithiasis is a benign pathology, but its evolution remains unpredictable. The diagnosis is based on the combination of fibroscopy and chest CT, but may remain a surgical discovery. The most feared complications are the damage to the underlying lung and fistulization in the mediastinal structures, mainly the esophagus, the discovery of which may also be fortuitous at the surgical stage. Management is based on therapeutic abstention in case of asymptomatic broncholithiasis. Bronchial fibroscopy and surgical excision are the main therapeutic options for symptomatic or complicated broncholithiasis. the interest of these two clinical cases that they report the incidental discovery, either in the diagnosis of the broncholithiasis or at the stage of complications.

\section{Conflict of Interest}

The authors declare that they have no conflict of interest with this manuscript.

\section{References}

[1] Ketata, W., Ghrairi, H., Abid, H., Ammar, J., Jallouli, M., Marghli, A., et al. (2006) Broncholithiasis: A Rare but Potentially Serious Pathology. Revue des Maladies Respiratoires, 23, 10S109-10S139.

[2] Nollet, A.S., Vansteenkiste, J.F. and Demedts, M.G. (1998) Broncholithiasis: Rare but Still Present. Respiratory Medicine, 92, 963-965. 
https://doi.org/10.1016/S0954-6111(98)90197-4

[3] Beom Seo, J., Song, K.S., Seong Lee, J., Mo Goo, J., Young Kim, H., Song, J.W., et al. (2002) Broncholithiasis: Review of the Causes with Radiologic-Pathologic Correlation. Radio Graphics, 22, S199-S213.

https://doi.org/10.1148/radiographics.22.suppl_1.g02oc07s199

[4] Ghraïri, H., Ketata, W., Kartas, S., Ayadi, A., Ammar, J., Abid, H., et al. (2007) Broncholithiasis: Six Observations. Revue De Pneumologie Clinique, 63, 94-99. https://doi.org/10.1016/S0761-8417(07)90107-8

[5] McLean, T.R., Beall, A.C. and Jones, J.W. (1991) Massive Hemoptysis Due to Broncholithiasis. The Annals of Thoracic Surgery, 52, 1173-1175. https://doi.org/10.1016/0003-4975(91)91307-H

[6] Ford, M.A.P., Mueller, P.S. and Morgenthaler, I.T. (2005) Bronchoesophageal Fistula Due to Broncholithiasis: A Case Series. Respiratory Medicine, 99, 830-835. https://doi.org/10.1016/j.rmed.2004.12.004

[7] Ferretti, G., Coulomb, M., Blanc-Jouvan, F., Ranchoup, Y., Pittet-Barbier, L. and Thony, F. (1994) Diagnosis of Broncholithiasis: The Role of High Resolution Computed Tomography. Journal de Radiologie, 75, 531-536.

[8] Dixon, G.F., Donnerberg, R.L., Shonfeld, S.A. and Whitcomb, M.E. (1984) Advances in the Diagnosis and Treatment of Broncholithiasis. The American Review of Respiratory Disease, 129, 1028-1030.

[9] Attia, S., Boussoffara, L., Fkih, L., Belhabib, S., Fenniche D. and Megdiche, M.L. (2006) Broncholithiasis. Revue des Maladies Respiratoires, 23, 348-352.

https://doi.org/10.1016/S0761-8425(06)71601-1

[10] Cole, F.H., Khandekar, A. and Watson, D.C. (1986) Management of Broncholithiasis: Is Thoracotomy Necessary? The Annals of Thoracic Surgery, 42, 255-257. https://doi.org/10.1016/S0003-4975(10)62728-2

[11] Olson, E.J., Utz, J.P. and Prakash, U.B. (1999) Therapeutic Bronchoscopy in Broncholithiasis. American Journal of Respiratory and Critical Care Medicine, 160, 766-770. https://doi.org/10.1164/ajrccm.160.3.9810021

[12] Noël-Savina, E., Le Mée, D., Tanguy-Lainé, K. and Descourt, R. (2012) Atteinte oesophagienne d'une tuberculose. Revue De Pneumologie Clinique, 68, 361-363. https://doi.org/10.1016/j.pneumo.2012.07.003

[13] Hodgson, N.C. and Inculet, R.I. (2000) Acute Airway Obstruction Secondary to Bilateral Broncholithiasis. Chest, 117, 1205-1207. https://doi.org/10.1378/chest.117.4.1205 